\title{
Biomass Reburning - Modeling/Engineering Studies
}

\author{
Quarterly Report No. 11 for Period
}

April 1 - June 30, 2000

Prepared by:

Mark Sheldon, Antonio Marquez, and Vladimir Zamansky

July 27,2000

DOE Contract No. DE-FC26-97FT97270

Submitted by:

GE Energy and Environmental Research Corporation

18 Mason, Irvine, CA 92618 


\section{$\underline{\text { Disclaimer }}$}

This report was prepared as an account of work sponsored by an agency of the United States Government. Neither the United States nor any agency thereof, nor any of their employees, makes any warranty, express or implied, or assumes any legal liability or responsibility for the accuracy, completeness, or usefulness of any information, apparatus, product, or process disclosed, or represents that its use would not infringe privately owned rights. Reference herein to any specific commercial product, process, or service by trade name, trademark, manufacturer, or otherwise does not necessarily constitute or imply its endorsement, recommendation, or favoring by the United States Government or any agency thereof. The views and opinions of authors expressed herein do not necessarily state or reflect those of the United States Government or any agency thereof. 


\begin{abstract}
This project is designed to develop engineering and modeling tools for a family of $\mathrm{NO}_{\mathrm{x}}$ control technologies utilizing biomass as a reburning fuel. During the eleventh reporting period (April 1 - June 30, 2000), EER and NETL R\&D group continued to work on Tasks 2, 3, 4, and 5. This report includes results from Task 3 physical modeling of the introduction of biomass reburning in a working coal-fired utility boiler.
\end{abstract}




\section{Table of Contents}

Section $\quad \underline{\text { Page }}$

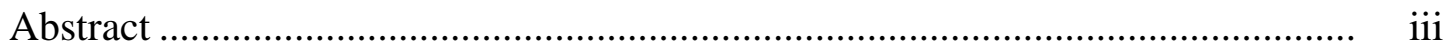

1.0 Project Status and Progress during the Reporting Period ................................. 1

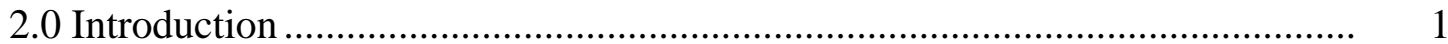

3.0 Biomass Reburning and Advanced Biomass Reburning Technologies ............ 2

4.0 Preliminary Process Design .......................................................................

5.0 Physical Flow Modeling Results ..................................................................... 6

6.0 Summary and Conclusions......................................................................... 13

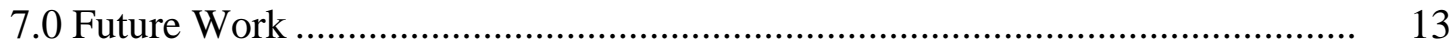

\section{List of Figures}

$\underline{\text { Section }} \quad \underline{\text { Page }}$

1. Injection locations for reburning study ………………...................................

2. 19\% Biomass reburn - dispersion profiles ....................................................... 11

3. 15\% Biomass reburn - dispersion profiles ....................................................... 12

\section{List of Tables}

$\underline{\text { Section }} \quad \underline{\text { Page }}$

1. Fuel analysis ......................................................................................

2. Reburning cases studied ...............................................................................

3. Material balance summary for baseline operation at 100\% MCR ...................... 7

4. Material balance summary for 19\% biomass reburning (Case 1) …………........ 8

5. Material balance summary for $15 \%$ biomass reburning (Case 2) ....................... 9 


\section{Project Status and Progress During the Reporting Period}

This project is designed to develop engineering and modeling tools for a family of $\mathrm{NO}_{\mathrm{x}}$ control technologies utilizing biomass as a reburning fuel. Basic and advanced biomass reburning technologies have the potential to achieve $60-90+\% \mathrm{NO}_{\mathrm{x}}$ control in coal fired boilers at a significantly lower cost than SCR. Project participants include: GE Energy and Environmental Research Corporation (EER), NETL R\&D group, Niagara Mohawk Power Corporation (NMPC) and Antares, Inc. Project tasks, responsibilities of organizations, and current task status are as follows:

1. Kinetic Modeling of Biomass Reburning (EER) - completed

2. Computational Fluid Dynamics (CFD) Modeling (NETL) - in progress

3. Physical Modeling (EER) - completed

4. Biomass Preparation Economics (NETL) - in progress

5. Evaluation of Slagging and Fouling (NETL) - in progress

6. Reburning vs. Cofiring Evaluation (Antares) - completed

7. Project Management and Reporting - in progress

This NETL project is conducted in close coordination with EER's Phase II SBIR project funded by USDA. The division of tasks between the two projects was thought out to keep process optimization and design tasks within the SBIR project. The NETL project involves modeling activities, economic studies of biomass handling, and experimental evaluation of slagging and fouling.

During the reporting period, project activities included physical flow modeling (Task 3), CFD studies (Task 2 - NETL), and Management/Reporting (Task 7).

As noted in previous reports, Niagra Mohawk withdrew from a proposed demonstration agreement following a change in ownership. At this time, a host site agreement has not yet been reached with any other candidate site. To complete the program objectives, process design work has begun on the basis of a typical boiler design. The boiler selected is a tangentially fired furnace using coal as the primary fuel. EER has previously conducted reburning studies on this boiler, and so already has the benefit of experience for evaluating this unit. This report includes the results of physical flow modeling.

\section{Introduction}

GE Energy and Environmental Research Corporation (GE EER) developed a methodology for the scale up and application of reburning technologies to coal-fired boilers. This methodology has been successfully used for design of reburning systems employing natural gas and coal as the reburning fuel. One of the objectives of GE EER's biomass reburning studies is to adapt this methodology to the design of a reburning system using biomass as the reburning fuel. This methodology will then be used to design a full-scale system for a coal-fired boiler in a demonstration of the technology. At this time, GE EER has not identified a specific host site for the demonstration phase of the project. Therefore, the studies will be performed on a typical coal-fired boiler. A tangentially-fired boiler which has previously been studied for reburning retrofit was selected as the basis for the present study. 
Reburning is a staged combustion process, for which $\mathrm{NO}_{\mathrm{x}}$ reduction is largely dependent on stoichiometry, residence time, and temperature. For this reason the quality of mixing of reburning process streams is of primary importance. To address this need, GE EER has developed a Physical Modeling methodology to evaluate the quality of mixing in a specific installation.

The following sections include a brief description of the reburning and advanced reburning process, and the results of physical flow modeling studies in which two reburning scenarios were examined.

\section{Biomass Reburning and Advanced Biomass Reburning Technologies}

Reburning is a combustion modification technology that removes $\mathrm{NO}_{\mathrm{x}}$ from combustion products by using fuel as a reducing agent and is based on the principle that hydrocarbon fragments can react with NO. Reburning can be applied to any type of utility boiler firing configuration. The reburning fuel can be the same as the primary fuel or it can be a different fuel such as coal, biomass, gas, or fuel oil. Conventional reburning technology is applied to a utility boiler by the staged addition of fuel and air to the boiler furnace following the main burners or primary combustion zone. The process can be divided conceptually into three zones.

Primary Zone: During reburning, the primary combustion zone will account for approximately 80 percent of the total heat input. In this zone, the primary fuel will be burned under fuel lean conditions. In most cases, the air/fuel ratio to the main burners can be reduced which will lower the initial $\mathrm{NO}_{\mathrm{x}}$ entering the reburning zone, and reduce the amount of reburning fuel necessary to achieve optimum conditions for $\mathrm{NO}_{\mathrm{x}}$ reduction in the reburning zone.

Reburning Zone: Above the main burners, additional fuel is added to create a slightly fuel rich environment or "reburning zone" which reduces nitrogen oxides formed in the primary combustion zone to molecular nitrogen. Depending upon the primary excess air level, the reburning fuel typically accounts for up to 20 percent of the total heat input. The process begins when hydrocarbon radicals formed from the reburning fuel in the fuel rich reburning zone, primarily $\mathrm{CH}$ species, react with $\mathrm{NO}$ from the primary zone to form other nitrogen species such as $\mathrm{HCN}$ and $\mathrm{NH}_{3}$. Once formed, these species rapidly react with other primary $\mathrm{NO}$ molecules to form molecular nitrogen $\left(\mathrm{N}_{2}\right)$. EER has extensively studied the reduction of NO to molecular nitrogen in the reburning process.

Burnout Zone: Following the reburning zone, overfire air is added to the boiler to produce overall lean conditions and to oxidize carbon monoxide and any remaining fuel fragments exiting the reburning zone. The remaining fixed nitrogen species will either be oxidized to $\mathrm{NO}_{\mathrm{x}}$ or reduced to molecular nitrogen.

In advanced reburning (AR) technology, a $\mathrm{NO}_{\mathrm{x}}$ reducing reagent (such as urea or ammonia) is added to the reburning process to further reduce $\mathrm{NO}_{\mathrm{x}}$ emissions. The reagent can be added before, with or after the overfire air depending upon the flue gas temperature at the point of overfire air injection. Typically advanced reburning performance is optimized at reburning fuel heat inputs on the order of $10 \%$, lower than for basic reburning. 


\section{Preliminary Process Design}

The boiler selected for the scale-up studies is a tangentially fired boiler manufactured by Combustion Engineering and has a rated capacity of $170 \mathrm{MW}$ (gross). The unit was designed to burn and presently fires Eastern bituminous coal with a nominal heating value of 12,381 Btu/lb. At full load firing pulverized coal, the unit has a gross heat input of 1,427 MMBtu/hr. The unit is equipped with low- $\mathrm{NO}_{\mathrm{x}}$ burners and close-coupled overfire air ports (CCOFA). There are four coal nozzles in the burners. One mill provides coal to the four nozzles located on the furnace corners at each elevation. Flue gas from the flames passes from the lower furnace into the upper furnace and then into the rear convective pass.

The biomass composition used for physical flow modeling studies is similar to that of pulverized furniture waste used in earlier pilot scale studies under this program. The composition parameters which were used as the basis for physical flow modeling are shown in Table 1 for both the coal used in this boiler and the biomass.

\section{TABLE 1. FUEL ANALYSIS}

Ultimate Analysis (Wet)
\begin{tabular}{|l|r|r|r|}
\cline { 3 - 4 } \multicolumn{2}{l|}{} & Coal & Biomass \\
\hline $\mathrm{H}$ & wt. \% & 72.750 & 49.865 \\
$\mathrm{~N}$ & wt. \% & 4.330 & 5.615 \\
$\mathrm{~S}$ & wt. \% & 1.380 & 0.518 \\
$\mathrm{O}$ & wt. \% & 0.780 & 0.028 \\
$\mathrm{Cl}$ & wt. \% & 5.580 & 35.260 \\
Ash & wt. \% & 0.000 & 1.212 \\
$\mathrm{H} 2 \mathrm{O}$ & wt. \% & 8.710 & 0.176 \\
Total & wt. \% & 6.470 & 7.327 \\
\cline { 3 - 4 } & wt. \% & 100.000 & 100.000 \\
Higher HV & Btu/lb & 12,381 & 7,884 \\
\hline
\end{tabular}
Eastern Bituminous coal currently fired
at example plant.
2 Furniture Waste used in earlier
experimental studies

Results of experimental studies of biomass reburning conducted under the coordinated USDA SBIR program, presented in previous quarterly reports, suggest that for reburn systems using biomass similar to this furniture waste, the optimum basic reburn fuel heat input could be as low at $15 \%$. This is lower than the $20 \%$ which is typical for reburning systems based on other fuel types. For the purposes of preliminary design studies, two cases within this range of basic reburning heat input were selected for the physical modeling study. As shown in Table 2, the first case is reburning with 19\% of the fuel heat input from biomass, and the second is $15 \%$ biomass reburning. The other parameters in the table describe the injection parameters for these cases. $19 \%$ reburning corresponds to a reburn zone stoichiometric ratio (SR) of 0.90 , the value typically chosen for other types of reburn fuel. 15\% reburning, which may provide better performance for some biomass types as previously noted, corresponds to a reburn zone SR of 0.95 . 
TABLE 2. REBURNING CASES STUDIED

\begin{tabular}{ccccccc}
\hline Case \# & \% Reburn & \% FGR & $\begin{array}{c}\text { FGR/BioMass } \\
\text { Ratio }\end{array}$ & $\begin{array}{c}\text { Reburn Fuel } \\
\text { Jet Vel }(\mathrm{ft} / \mathrm{s})\end{array}$ & $\begin{array}{c}\text { HP-OFA Jet } \\
\text { Vel }(\mathrm{ft} / \mathrm{s})\end{array}$ & $\begin{array}{c}\text { LP-OFA Jet } \\
\text { Vel (ft/s) }\end{array}$ \\
\hline 1 & 19 & 6 & 2.46 & 191 & 146 & 119 \\
2 & 15 & 7 & 3.70 & 222 & 146 & 83 \\
\hline
\end{tabular}

These SR's assume that the carrier gas used to inject biomass into the furnace has a relatively low oxygen content, otherwise larger amounts of reburning fuel would be required to achieve the same reburn zone chemistry. For this reason, the preliminary process design is based on Flue Gas Recirculation (FGR) as a readily available source of low-oxygen gas. The relative amount of FGR, 6 to $7 \%$ of the total flue gas flow rate, was selected based on the mass flow and velocity requirements calculated for good mixing of the biomass-laden fuel jet. For both cases, the FGR would mix with the biomass to a temperature of about $\sim 170^{\circ} \mathrm{F}$, and take the biomass reburn fuel from the mill to the boiler in 4-15 inch I.D. pipes with a transport velocity of approximately $4,800 \mathrm{ft} / \mathrm{min}$. At the boiler, the available pressure in the line would be used to neck down to the nozzle size and obtain the required injection velocity. The maximum nozzle pressure loss will be on the order of 12 in wg so the required pressure would be the 12 in wg plus the line losses. The mass ratio of FGR to biomass, 2.5 to 3.7 for the cases studied, is comparable to that employed in typical reburning systems using other types of solid fuel such as coal. The requirements for good transport of biomass within the carrier lines are an issue for future development of this technology.

GE EER has identified a preliminary approach for locating basic and advanced biomass reburning injectors for the subject unit. In both processes, the reburning fuel would be injected at an elevation above the main burners, and the overfire air would be injected at an elevation selected to provide the maximum reburning zone residence time within the furnace constraints. As shown in Figure 1, the reburning fuel injectors would be located approximately eight feet above the CCOFA, which represents the upper part of the primary zone injectors. This elevation is chosen to provide sufficient separation between the main flames and the reburning zone to ensure good reburning performance. Overfire air injectors for the burnout zone (not to be confused with the primary burner's CCOFA) would be located on the furnace corners at an elevation approximately ten feet above the reburning fuel injectors. The overfire air system design must provide for good control over carbon monoxide emissions and burnout of the biomass and coal particles.

The reburning fuel injectors would be installed on each corner of the furnace to promote mixing of the reburning fuel. For the use of biomass as a reburning fuel, preliminary calculations suggest that the use of a total of four injectors would result in effective mixing of the reburning fuel with the furnace gases. Each injector consists of a single reburning fuel nozzle with a diameter of approximately 9.5 inches. Injection velocities in the range of 190-220 feet/sec were calculated to achieve good mixing of the reburning fuel in the range of 19 to $15 \%$ reburn fuel heat input, with lower velocities required at the higher reburn fuel flow rate. 


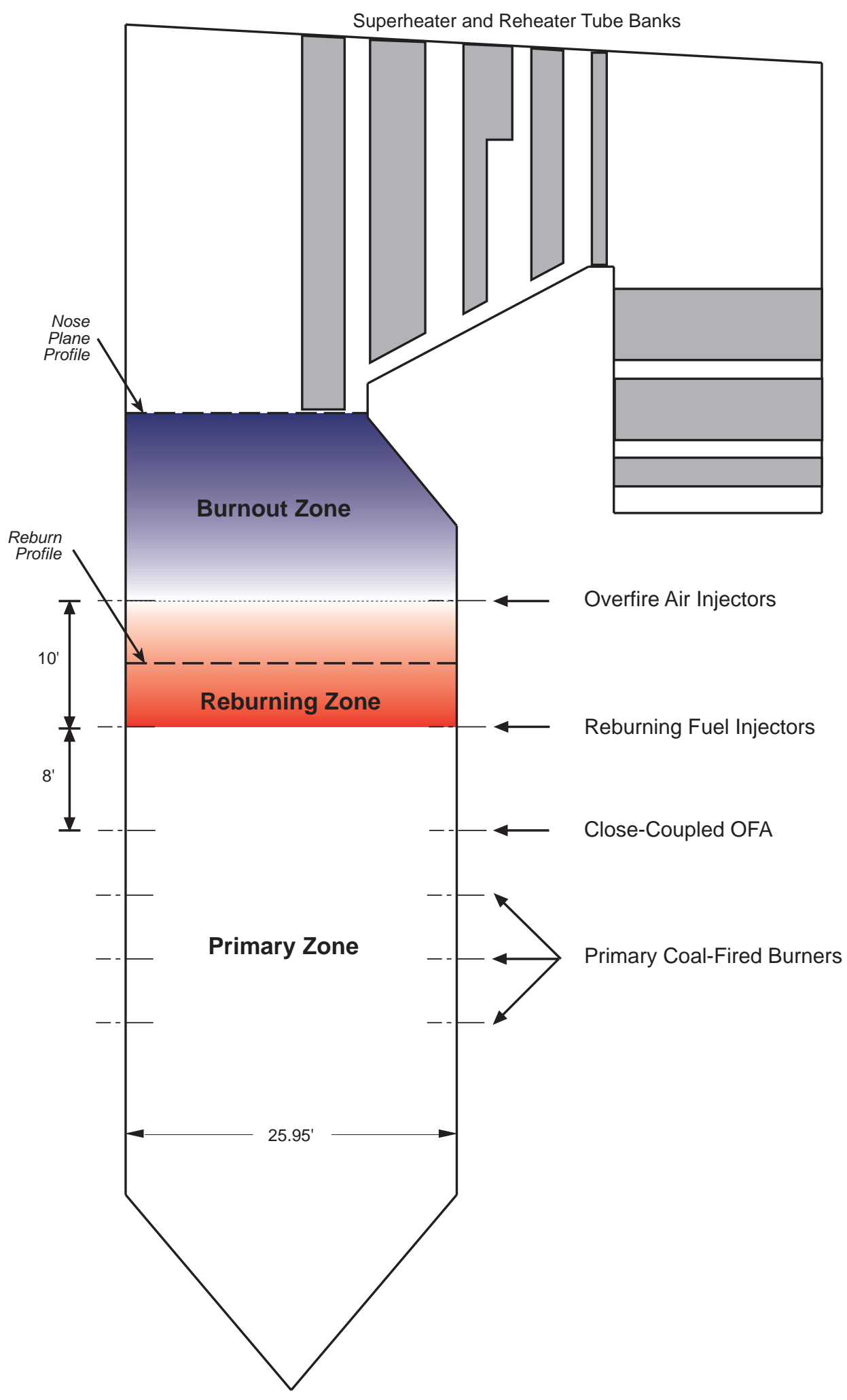

Figure 1. Injection locations for reburning study. 
The overfire injection system would consist of four dual-compartment OFA injectors installed at each corner of the furnace. They can also be used for injection of $\mathrm{N}$-agent (ammonia or urea) if the system is operated in the AR mode. The dual-compartment OFA injectors consist of a constant velocity inlet and a modulating velocity inlet. This feature permits individual tuning of the OFA injectors to bias flow conditions according to furnace flow patterns, and the capability of operating over a wider range of reburning conditions. The design which was studied employed a modulated low-pressure air inlet immediately above the high-pressure, constant velocity inlet. A velocity of about $146 \mathrm{ft} / \mathrm{s}$ was calculated for the constant velocity port, with the modulating zone velocity increased from 83 to $119 \mathrm{ft} / \mathrm{s}$ as reburn heat input increased from 15 to $19 \%$.

Material balances for this unit with and without reburning are shown in Tables 3 through 5. The baseline material balance in Table 3 represents current operation without reburning. The biomass reburning mass balances are based on MCR operation (170 MW). The primary excess air level in the burners would be lowered from $20 \%$ to $10 \%$ in order to minimize the amount of reburning fuel needed to achieve a specific $\mathrm{NO}_{\mathrm{x}}$ emissions target. Sufficient overfire air would be added to bring the boiler up to its normal operating excess air level of $20 \%$. The material balances shown for $19 \%$ reburning are shown in Table 4 , and for $15 \%$ reburning in Table 5.

\section{Physical Flow Modeling Results}

Physical flow modeling provides a way to visualize and quantify the mixing performance of a reburning injection system. Since reburning performance is strongly dependent on local stoichiometry and on residence time, rapid and uniform mixing of reburning and burnout air (OFA) jets is critical to optimized $\mathrm{NO}_{\mathrm{x}}$ control.

In a physical flow modeling study, the first step is to construct a subscale isothermal flow model of the host boiler. The physical model is typically 1:12 geometric scale and includes all of the important features of the host site furnace. The model will simulate the region along the combustion flow path from the burners to the first few tube banks of the convective pass. The present study focused on a boiler which had previously been modeled for reburning, so a physical flow model was already available and needed only some adjustments to simulate the proposed biomass reburning injection system.

Initially, the furnace flow field was visually assessed. The model is constructed of transparent material to facilitate visual observation. Smoke injection through selected inlets provides a visual indicator of the mixing behavior of those inlets in the overall furnace flow. These observations were used to assess the preliminary design and ensure that the injection design is basically operating correctly, prior to conducting more time-consuming quantitative measurements.

The proposed injection systems were then evaluated by conducting tracer dispersion measurements. In this technique, a small amount of a tracer gas such is added to the jets which represent reburning fuel or overfire air. The tracer concentration profiles are measured downstream of the injection system. These measurements provide a map of the effectiveness of the system in dispersing the tracer. The tracer concentrations are used to calculate the corresponding local stoichiometries which would be encountered in the actual system. The map of local stoichiometries can be used to compare the effectiveness of different injection systems in 
TABLE 3. MATERIAL BALANCE SUMMARY FOR BASELINE OPERATION AT 100\% MCR.

SR:

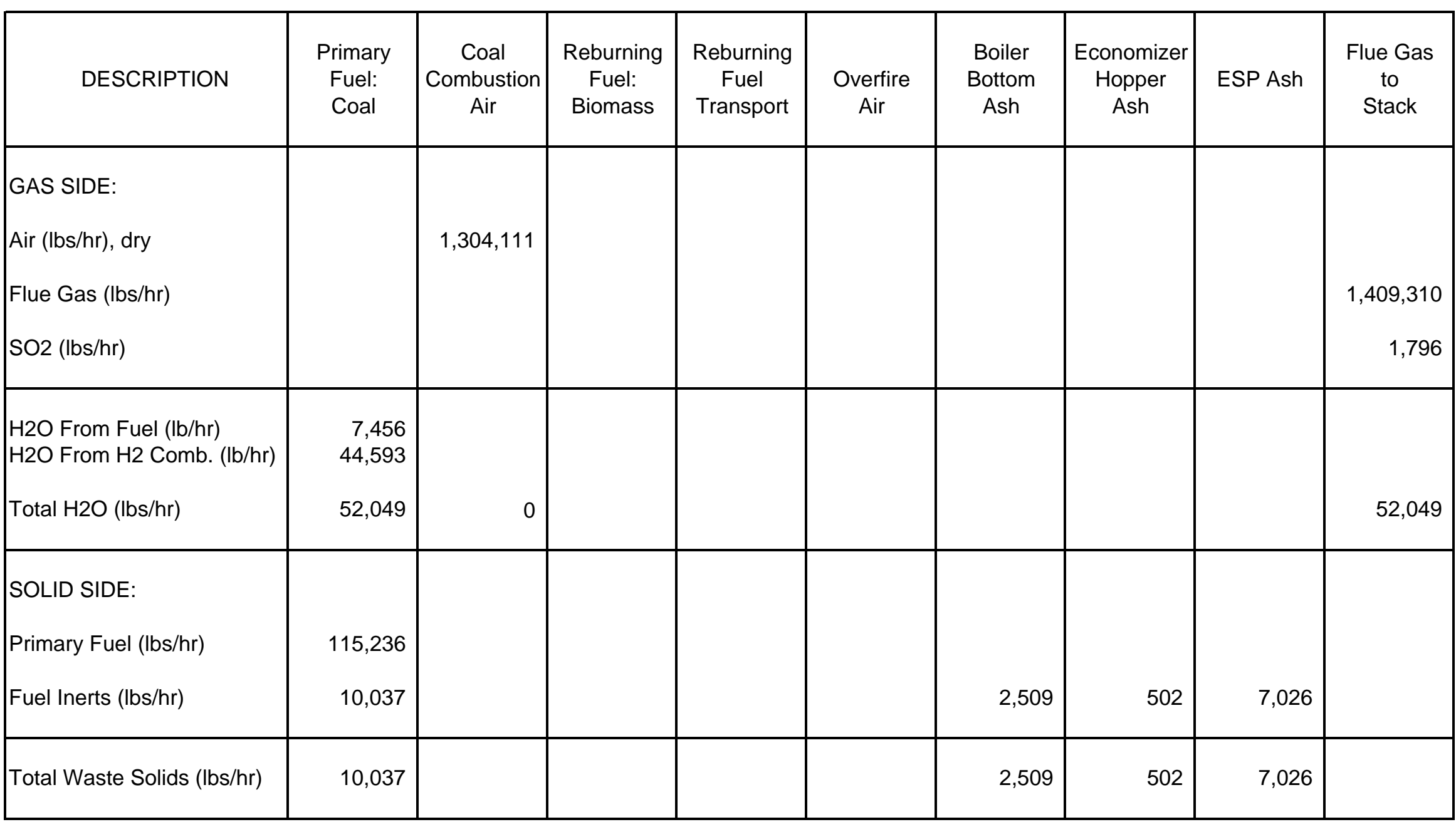


TABLE 4. MATERIAL BALANCE SUMMARY FOR 19\% BIOMASS REBURNING (CASE 1).

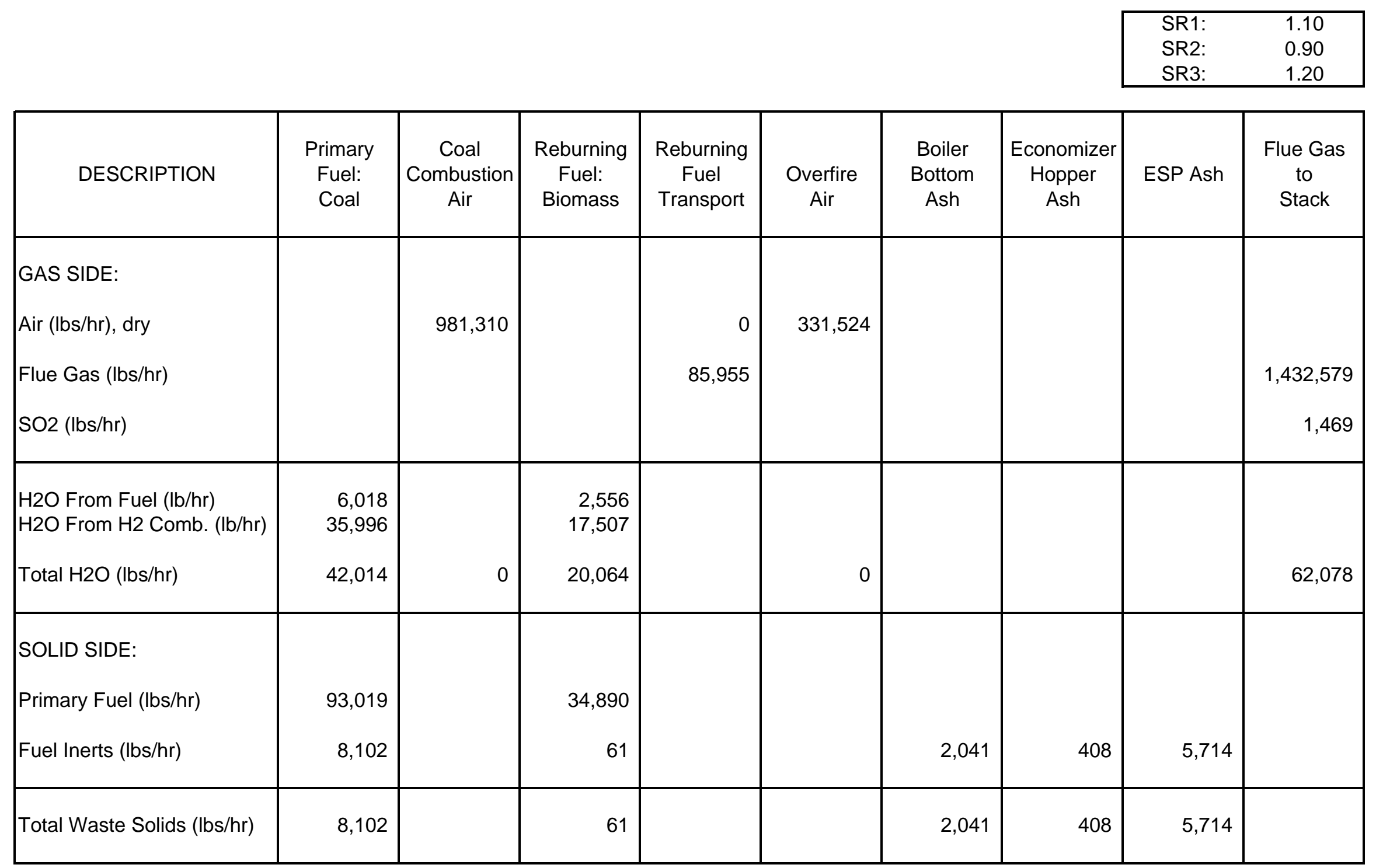


TABLE 5. MATERIAL BALANCE SUMMARY FOR 15\% BIOMASS REBURNING (CASE 2).

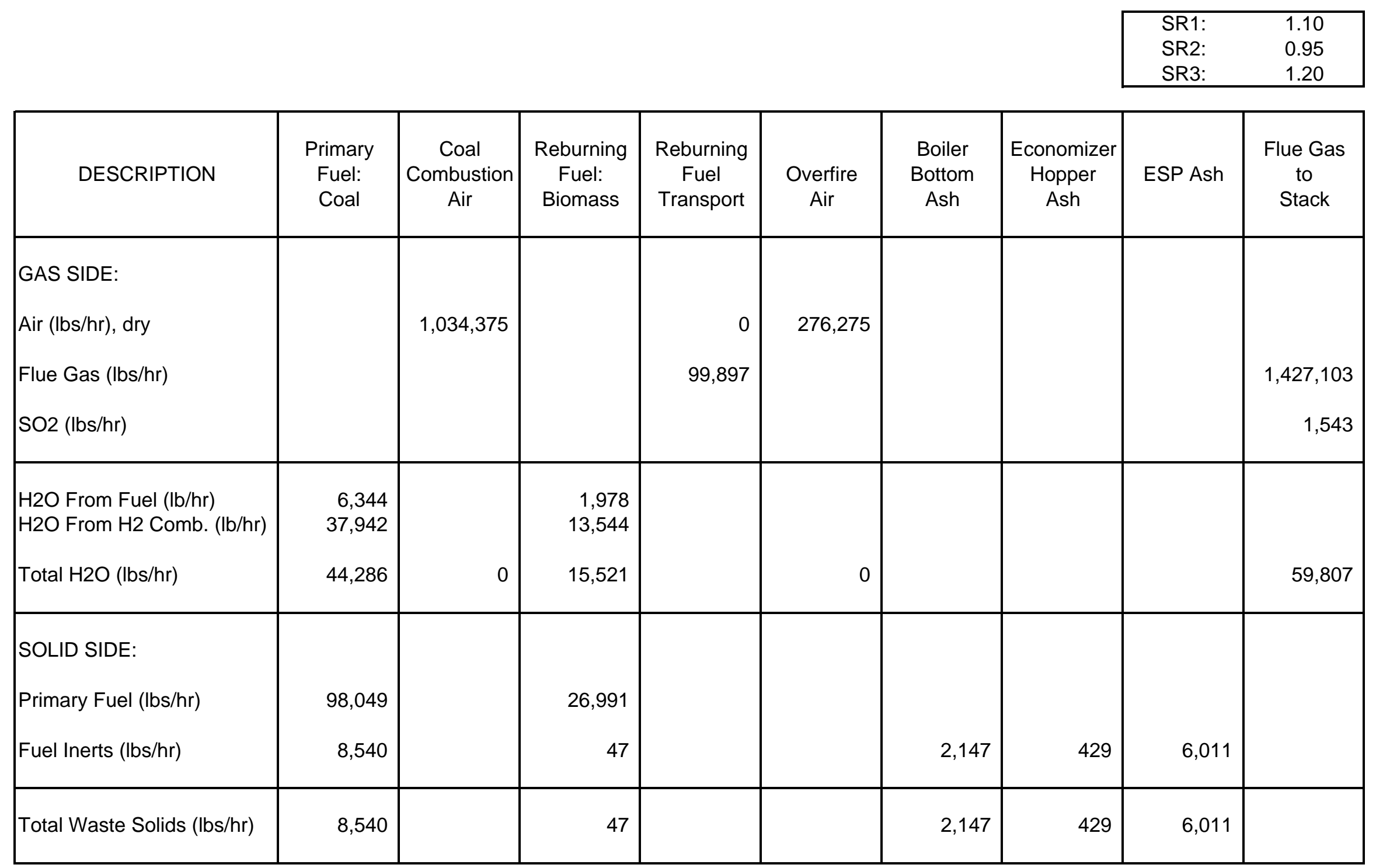


mixing the reburning fuel, overfire air, and $\mathrm{N}$-agent for the AR mode, as an aid for assessing the relative impacts on $\mathrm{NO}_{\mathrm{x}}$ reduction.

Figures 2 and 3 show the dispersion profiles for the two cases of biomass reburning that were tested using the isothermal flow model. The two cases presented previously in Table 2, represent 15 percent (SR2 0.95) and 19 percent (SR2 0.90) reburning. For each case, two dispersion profiles where performed. The reburn zone profile is performed at about the mid-point between the reburn fuel injectors and the overfire air injectors. The overfire air profile is performed at the nose plane. The measured data is then converted to stoichiometric ratio, statistically analyzed, and present in the contour plots shown on the figures. The contours are labeled by the calculated local stoichiometric ratio, which may be compared to the mean stoichiometric ratio for the region. As shown in the figure legends, the mean SR for the reburn zone is 0.90 for Figure 2 (19\% reburn) and 0.95 for Figure 3 (15\% reburn), and the mean SR for the burnout zone (nose plane) is 1.20 for both cases.

The following observations were made based on these results:

- The 19 percent reburning case shows spotty coverage around a center swirling core that is typical of tangentially fired boilers. The reburn fuel profile shows the typical four low stoichiometric regions where the concentration of the reburn fuel jets is highest. Those four regions surround the center of the cyclone where the stoichiometric ratios are relatively high because of the difficulty in penetrating this highly cyclonic region. This profile is consistent with results obtained during the gas reburning modeling study conducted previously for this same unit.

- The 19 percent overfire air case shows a large low stoichiometric region near the back wall. The front right and rear right OFA injectors typically cover this area. In this case, it appears that poor coverage of this area is due to the overfire air jets entraining into the main cyclone and bypassing this region. This was not observed during the gas reburning case, but it seems to be caused by slight changes in the flow field caused by the high mass flow added in the reburning zone. This assessment was confirmed by turning off the reburning flow and observing the behavior and the coverage provided by the right side jets.

- The 15 percent reburning mixing case is almost identical to the 19 percent case. This was by design and it is the reason for raising the \% FGR from 6 to 7 percent and the nozzle conditions from $191 \mathrm{ft} / \mathrm{s}$ to $222 \mathrm{ft} / \mathrm{s}$.

- The overfire air profile for $15 \%$ reburning case shows that the low stoichiometric zone has shifted to the left side of the boiler. Again, the sensitivity of the jets to the flow field is causing some regions to show nonideal distribution.

The Coefficient of Variance (COV) for each stoichiometry profile is listed in the legend for each figure. The values obtained for these cases are within the range of acceptable, but not optimized, operation. Although these profiles are not optimized, it appears that additional modeling work could result in improved mixing and dispersion of the reburning fuel and overfire air. There are several parameters which could be adjusted to improve mixing performance including jet inlet dimensions, quantity of carrier gas, and jet velocities. Detailed optimization studies are necessarily specific to the particular installation, and the additional effort is not justified in this 


\begin{tabular}{|c|c|c|c|c|c|}
\hline Boiler Load & $\overline{\text { Full }}$ & & OFA Jet Parameters & & \\
\hline Reburn Heat Input & 19.3 & $\%$ & No. of Jets & 4 & \\
\hline SR (Burners) & 1.10 & & HP Flow & 45 & $\%$ \\
\hline SR (Reburn) & 0.90 & & HP OFA & & \\
\hline SR (Final) & 1.20 & & Jet Velocity & 146 & $\mathrm{ft} / \mathrm{s}$ \\
\hline FGR & 6.00 & $\%$ & Velocity Head & 2.50 & "WG \\
\hline RF Transport Medium & FGR & & $L P O F A$ & & \\
\hline RF Transport Temp. & 170 & ${ }^{\circ} \mathrm{F}$ & Jet Velocity & 119 & $\mathrm{ft} / \mathrm{s}$ \\
\hline RF Boost & None & & Velocity Head & 1.65 & "WG \\
\hline \multicolumn{6}{|c|}{ Reburn Fuel Jet Parameters } \\
\hline Number of Jets & 4 & & & & \\
\hline Jet Diameter & 9.5 & in & Test Results & & \\
\hline Jet Velocity & 191 & $\mathrm{ft} / \mathrm{s}$ & RF COV. & 0.48 & \\
\hline Velocity Head & 9.8 & in wg & OFA COV. & 0.46 & \\
\hline
\end{tabular}
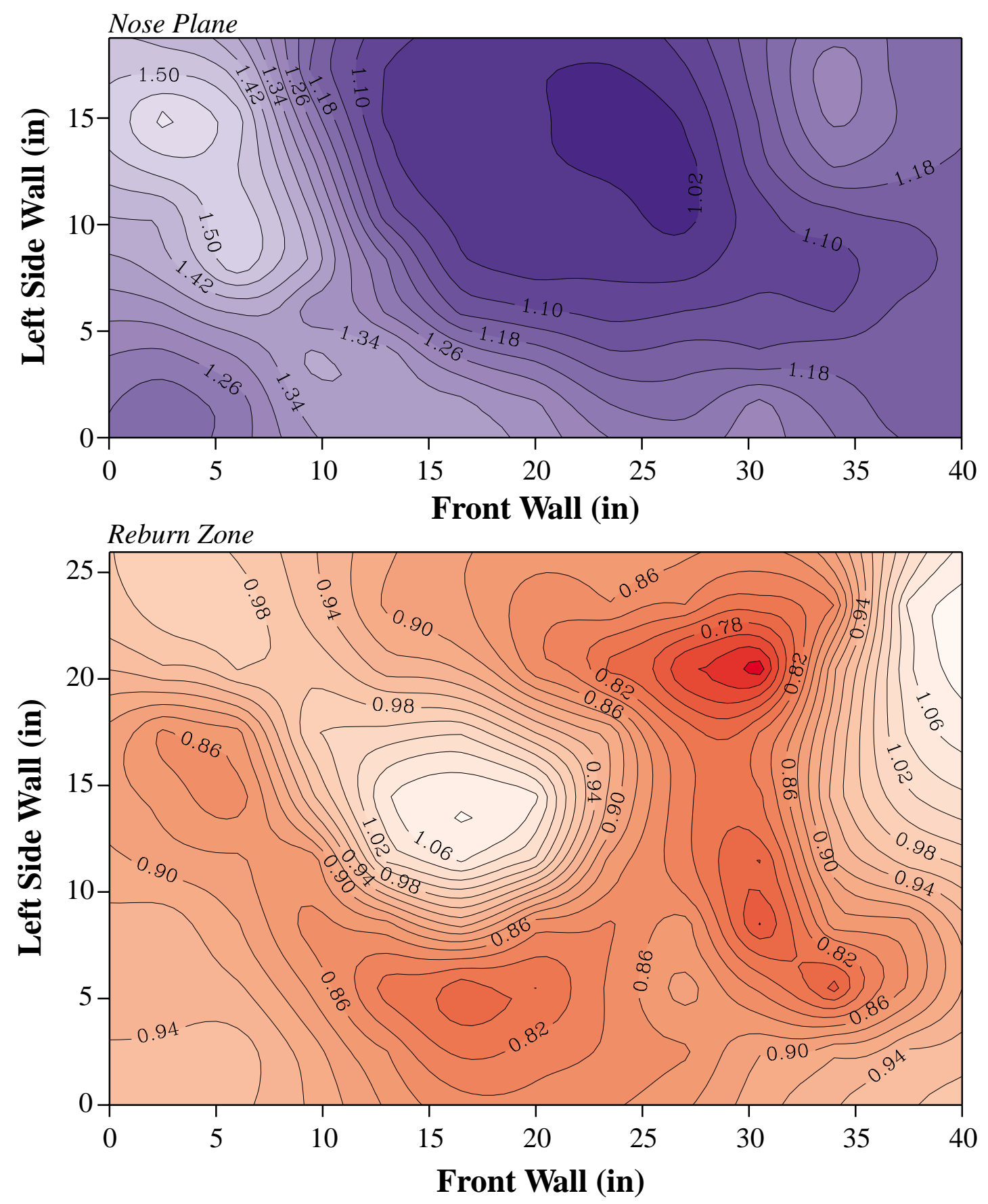

Figure 2. 19\% biomass reburn - dispersion profiles 


\begin{tabular}{|lrl|lrl|}
\hline Boiler Load & Full & & OFA Jet Parameters & & \\
Reburn Heat Input & 14.9 & $\%$ & No. of Jets & \\
SR (Burners) & 1.10 & & HP Flow & 54 & $\%$ \\
SR (Reburn) & 0.95 & & HP OFA & & \\
SR (Final) & 1.20 & & Jet Velocity & 146 & $\mathrm{ft} / \mathrm{s}$ \\
FGR & 7.00 & $\%$ & Velocity Head & 2.49 & "WG \\
RF Transport Medium & FGR & & LP OFA & & \\
RF Transport Temp. & 170 & ${ }^{\circ} \mathrm{F}$ & Jet Velocity & 83 & $\mathrm{ft} / \mathrm{s}$ \\
RF Boost & None & & Velocity Head & 0.80 & "WG \\
Reburn Fuel Jet Parameters & & & & & \\
$\quad$ Number of Jets & 4 & & & & \\
$\quad$ Jet Diameter & 9.5 & in & Test Results & & \\
Jet Velocity & 222 & ft/s & RF COV. & 0.48 & \\
Velocity Head & 12.0 & in wg & OFA COV. & 0.41 & \\
\hline
\end{tabular}
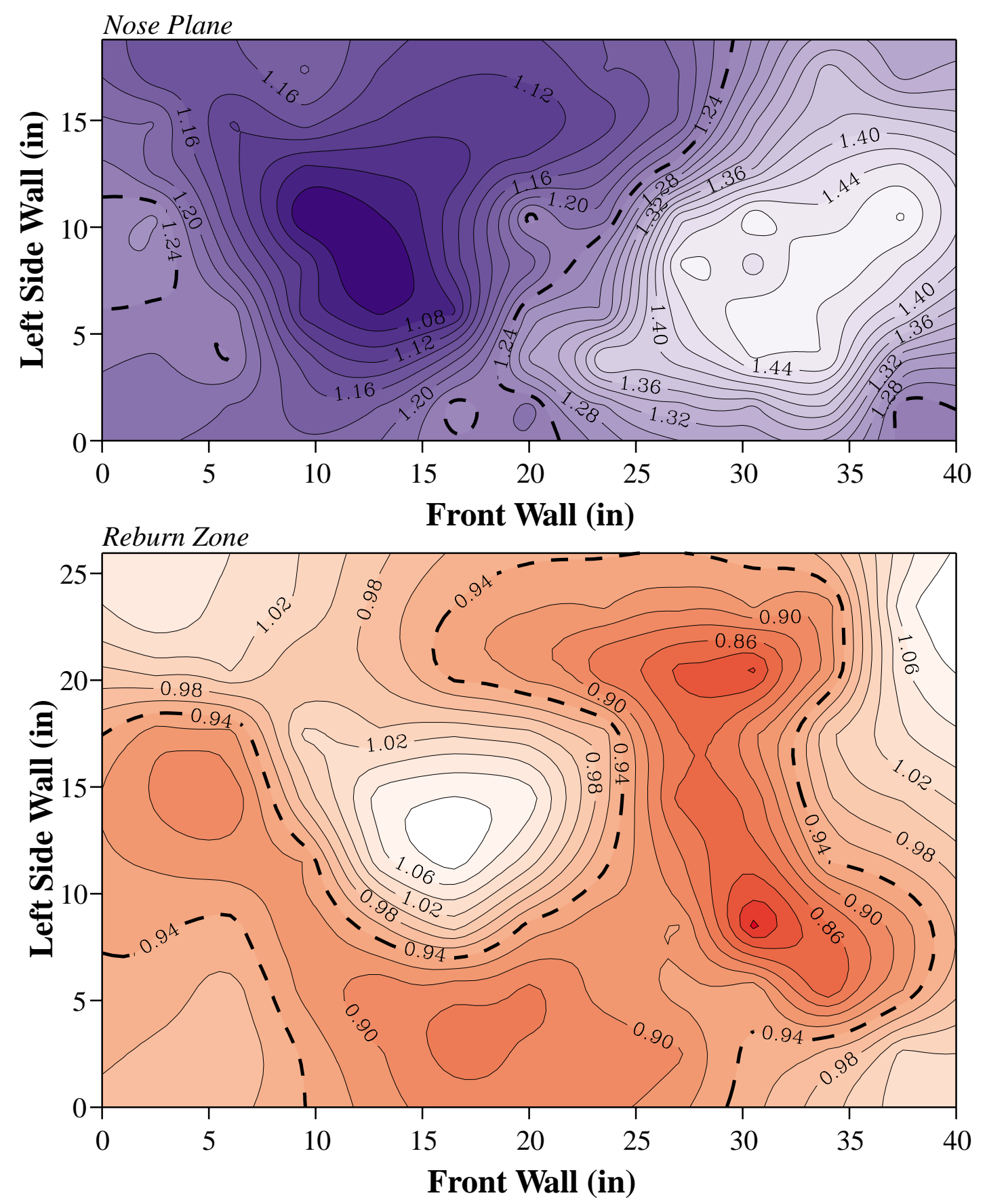

Figure 3. $15 \%$ biomass reburn - dispersion profiles 
generic design study. However, the present results indicate that once a specific host is identified, that this methodology may be used in designing an effective biomass reburning system.

\section{Summary and Conclusions}

The validated methodology for reburning system design has been applied to biomass reburning in a typical coal-fired boiler. This methodology includes the use of physical flow models to assess the mixing performance of reburn fuel and overfire air jets, which is of paramount importance in achieving target $\mathrm{NO}_{\mathrm{x}}$ control performance. The current study assessed the performance of the reburning system for two operating scenarios. The dispersion profiles of both the reburning zone and the overfire are zone were assessed to quantitatively determine the quality of mixing within each zone. The two preliminary cases studied showed potential as candidate reburning designs, and demonstrated that similar mixing performance could be achieved in operation with different quantities of reburning fuel. Refinement of the reburning system to achieve optimum performance is deferred until later studies on an actual host unit.

\section{Future Work}

It is anticipated that most or all of Tasks 2, 4 and 5 will be completed by NETL R\&D group during the next quarter. EER has concluded its work plan except for final analysis and report preparation. A draft final report will be completed at the end of August, 2000. 